\title{
UAV AND COMPUTER VISION, DETECTION OF INFRASTRUCTURE LOSSES AND 3D MODELING
}

\author{
V. Barrile ${ }^{a}$, G. Bilotta ${ }^{\text {b, }}{ }^{*}$, A. Nunnari ${ }^{\text {a }}$ \\ ${ }^{a}$ Geomatics Lab, DICEAM, Università Mediterranea di Reggio Calabria, 89123 loc. Feo di Vito, Reggio Calabria, Italy - \\ vincenzo.barrile@unirc.it, ninonunnari@hotmail.it \\ ${ }^{\mathrm{b}}$ Dept. of Planning, IUAV University of Venice, Santa Croce 191, Tolentini 30135 Venice, Italy - \\ giuliana.bilotta@iuav.it
}

KEY WORDS: 3D modeling, Structure from Motion, Infrastructures, Civil buildings, Degradation of buildings, Monitoring, UAV

\begin{abstract}
:
The degradation of buildings, or rather the decline of their initial performances following external agents both natural (cold-thaw, earthquake, salt, etc.) and artificial (industrial field, urban setting, etc.), in the years lead to the necessity of developing Non-Destructive Testing (NDT) intended to give useful information for an explanation of a potential deterioration without damaging the state of buildings. An accurate examination of damages, of the repeat of cracks in condition of similar stress, indicate the existence of principles that control the creation of these events. There is no doubt that a precise visual analysis is at the bottom of a correct evaluation of the building.

This paper deals with the creation of 3D models based on the capture of digital images, through autopilot flight UAV, for civil buildings situated on the area of Reggio Calabria. The following elaboration is done thanks to the use of commercial software, based on specific algorithms of the Structure from Motion (SfM) technique. SfM represents an important progress in the aerial and terrestrial survey field obtaining results, in terms of time and quality, comparable to those achievable through more traditional data capture methodologies.
\end{abstract}

\section{INTRODUCTION}

In the field of civil infrastructures, 3D reconstruction through images is an emerging theme, which is not fully developed yet commercially. Over the last few years, algorithms have been made widely available in the field of Geomatics, for making DEM models, and in the archaeological field for the modeling of cultural goods. SfM has been successfully used in a wide range of applications by generation of Photogrammetries, surveys and topographic mapping, for control activities, for assessing disaster-related disasters, and for the retention of evidence for legal dispute resolutions. Several studies have highlighted the precision and efficiency of this technique by highlighting preciousness and defects.

Here will be some studies conducted and aimed at the development of a scientific approach directed to the 3D modeling of facultative infrastructure works, not only to the geometric reconstruction, but also to the visual identification of the present depletions and to a global analysis of the state of conservation of the work. The use of more and more advanced technologies in the construction of large works allows not only to define the useful shape but also to adapt the old works to the requirements of the new and more stringent rules on seismicity and durability. Precisely in terms of durability, diagnostic and surveillance techniques are of fundamental importance for the assessment of the conservation status of the work. In identifying the causes of degradation, the working conditions and, of course, the materials that constitute the work must be taken into account. In general, it is possible to identify some of the typical causes of degradation briefly summarized in the following main points: environmental aggression, material durability, errors or deficiencies that must be imputed to the realization.
The first point should be investigated in the conditions in which the structure performs its function, not only the atmosphere, the climate or the water (meteoric, watercourse) but the micro environment with which the structure interacts (vibrations, actions of mechanical disruption caused by frost and thaw, chemical aggression caused by sulphates, chlorides, oils, etc.). The second point is to detect in the technological shortcomings of the materials used or in their erroneous detection according to the use. The third point should be considered the incorrect combination of materials and insufficient attention to the construction phase. The use of non-destructive investigations for the assessment of the state of conservation of works is a valuable tool both for the determination of the physical and mechanical properties of the structural elements that make up the work and for obtaining detailed information on the geometric survey of structures.

A well-established technique for modeling structures is, for the acquisition of raw data to be processed later, in the use of the Laser Scanner, which has now achieved remarkable results and remarkable precision. Through this technique, starting from a laser source, it is possible to scan the three-dimensional coordinates of a very high number of points (point clouds) automatically, allowing for a three-dimensional reconstruction of the object or surface of interest. Recently, through SfM that resembles what happens to stereoscopic photogrammetry (where the generation of 3D structure is resolved and defined by overlapping images), the scene reconstruction, positioning and orientation of the camera are automatically resolved by the software used for processing, speeding up work times and lowering costs.

\footnotetext{
* Corresponding author
} 


\section{OBJECT OF THE STUDY}

For this contribute three distinct works have been acquired by nature and complexity. First, was surveyed a bridge in reinforced concrete located in San Gregorio in the town of Reggio Calabria. It consists of three spans in reinforced concrete, each of which consists of five longitudinal beams of $13.75 \mathrm{~m}$ long, with a section of $0.40 \mathrm{mx} 0.70 \mathrm{~m}$, of $1.40 \mathrm{~m}$ which are connected by traversers having a section of $0.15 \mathrm{mx} 0.30 \mathrm{~m}$ spaced at a distance of $2.75 \mathrm{~m}$ (Figures 1 and 2). The artefact has several problems both with regard to metal reinforcements, in advanced oxidation state and in concrete, characterized by important and diffused areas affected by the separation of the concrete cover. It is therefore evident that there is a need for interventions aimed at the restoration and consolidation of all structural elements of the bridge (beams, traverses and slats), which cannot ignore the knowledge of the geometry of the various structural elements and the determination of the position, number and the section of the metal armatures.

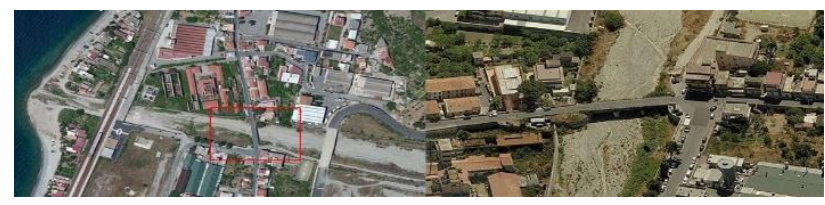

Figure 1. Position of the first work surveyed

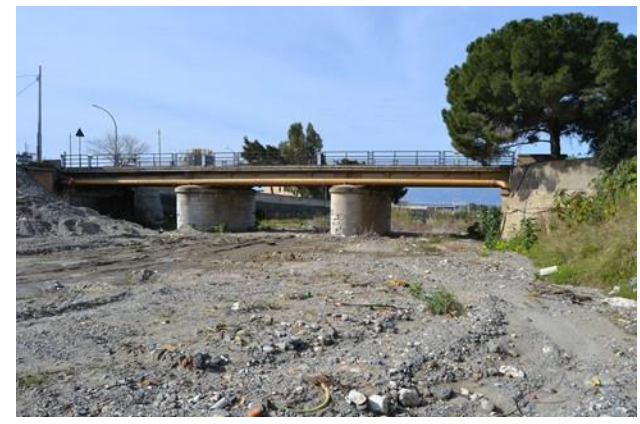

Figure 2. Detail of the San Gregorio Bridge

Always in San Gregorio, in the city of Reggio Calabria, a boxshaped road tunnel (Figures 3 and 4) was found, with a length of $100 \mathrm{~m}$ and a width of $11.80 \mathrm{~m}$, shoulders have a width of $1.30 \mathrm{~m}$ and a height of $5.50 \mathrm{~m}$, the concrete slab thickness is $1.30 \mathrm{~m}$. The work has not yet been completed and there are signs of efflorescence, moisture spots, due to bad or non-existent waterproofing (Bae, Golparvar-Fard, White, 2013).

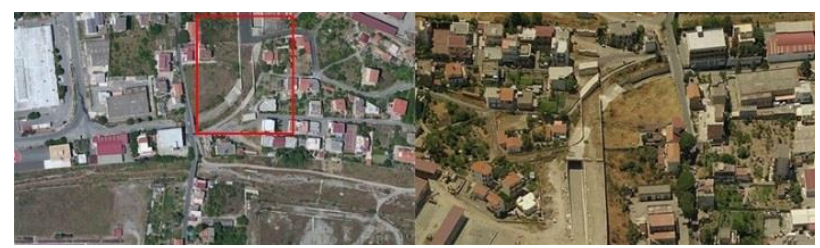

Figure 3. Position of the second work surveyed

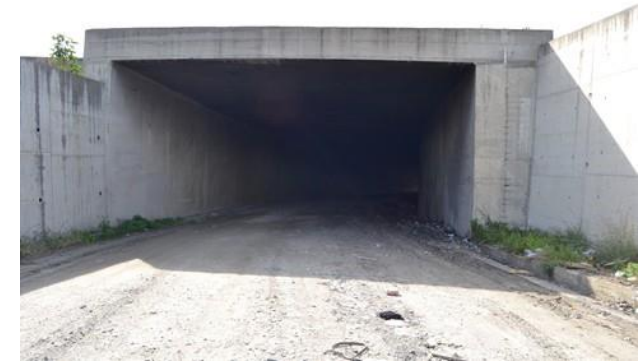

Figure 4. Detail of the tunnel entrance

The third surveyed work is a bridge located at $\mathrm{km} 517.20$ of the SS 18 in the Villa San Giovanni municipality in the province of Reggio Calabria (Figure 5 and 6). The work was chosen in view of its particular design; in fact, it is made up of an original masonry structure consisting of three spans with $6.60 \mathrm{~m}$ light and two $1.50 \mathrm{~m}$ wide poles with a length and a width of $27 \mathrm{~m}$ each $6.30 \mathrm{~m}$. This structure, following the adjustment and extension of the road section, was alongside a new in reinforced concrete, always at three lanes with lights of $7.20 \mathrm{~m}$, a width of $4.20 \mathrm{~m}$, also, length of $27 \mathrm{~m}$. They are commonly found in masonry work, missing or broken elements, efflorescence traces and a general degradation due to time spent and poor maintenance. The part in reinforced concrete has traits with concrete dilution, efflorescence, expulsion of the cover, spraying of the casting, losers, these, from a misalignment of the work.

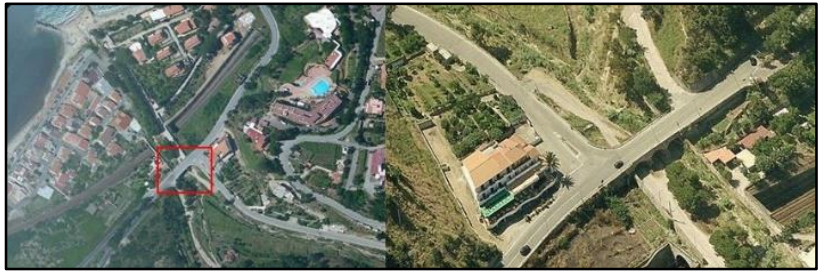

Figure 5. Bridge framing in Villa San Giovanni

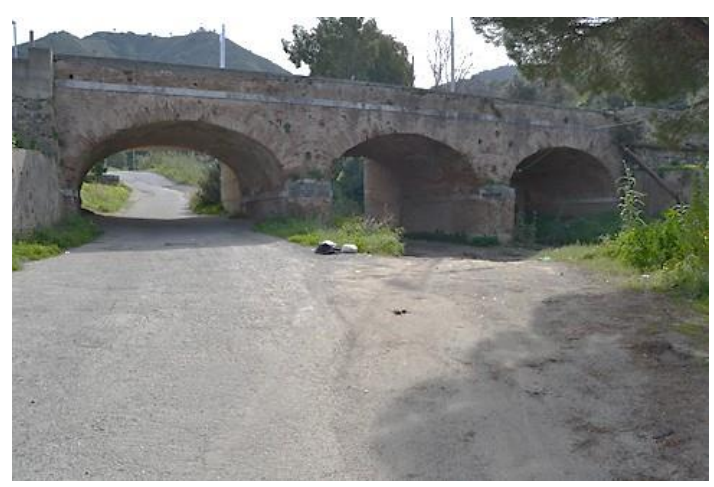

Figure 6. Detail of the bridge of Villa San Giovanni

\section{UNMANNED AERIAL VEHICLES}

Nowadays, in the common sense, UAV is associated with multirotor aircraft that are most commonly available on the market even though, strictly speaking, the term extends to any means capable of moving with a high degree of autonomy in controlling 
their behaviour in relation to the environmental situations in which it moves. This type of drone has been in existence for more than 8 years now but, at the present time, the novelties that bring them to the fore are:

- the collapse of prices and the wide variety of models available;

- their greater reliability and versatility;

- their consequent widespread diffusion.

Currently, in fact, an UAV can make photographic surveys useful for the objectives of reconstruction analysed in this article, costs even less than a thousand euros, resulting in an ever-increasing number of professionals. Their low cost also influences the survey cost, cheaper than cost related to the use of more traditional engineering tools and devices, and it is desirable that the inherent culture of these aircraft becomes increasingly part of the university education, as are the others instruments.

However, it is important to emphasize that drones are not simple model aircraft and require preparation for their use and maintenance. Moreover, their use is tightened strictly in most of the Western world and every survey must be done in compliance with current rules, as in the Italian case with the regulation issued by ENAC and recently updated. Unskillfulness and negligence can lead to dangerous behaviour for themselves and others, and risks of being incriminate of both administrative and criminal offenses.

\section{SURVEY AND RECONSTRUCTION OF WORKS THROUGH SFM}

The principle on which the SfM is based recalls what happens to digital stereoscopic photogrammetry, because $3 \mathrm{D}$ generation is done by overlapping images. The software used by particular algorithms automatically resolves both placement and orientation of the camera and the reconstruction of the model is done by means of point clouds. Because the software identifies points and targets in a completely automatic way, care should be taken to ensure that the shots are made in such a way as to ensure a high degree of overlap and therefore an adequate quality of the model. Workflow for obtaining a point cloud and its model is very simple. Through an algorithm implemented by D. Lowe in 2004, called SIFT (Scale Invariant Feature Transform), the notable points in the photographic shots are identified and extracted by operators of interest that, within particular areas of the scene, identify the points with equal lighting, colour, rotation, etc. Once the homologous points are identified, these are coupled through the matching operation using the Euclidean concept of distance. Locating a point in the first scene having certain characteristics (brightness, colour, etc.), the homologue in the next scene turns out to be the closest to the one in question. The next step involves generating the $3 \mathrm{D}$ model by determining the internal orientation parameters of the camera used for shooting. Bundle adjustment has the task of limiting errors during reconstruction. Last phase is the generation of the model through a dense cloud. Here are the dense image matching algorithms. They are distinguished in two types, area based matching algorithms (AMBs) that work on the statistical comparison of the grey intensity present in the various photos and which do not include the extraction of features by treating the intensity of the grey; and feature-based matching algorithms (FBM) that first search for common features and then perform extraction. The combination of both ensures optimum results but extends considerably the processing time.

The DJI Phantom 2 drone equipped with a GoPro HERO3+ Silver Edition digital camera was used to capture the photos for $3 \mathrm{D}$ reconstruction, which, thanks to its technical characteristics and ease of use, is well suited to uses of this type. The flights for the various surveys were set in automatic mode by the formulation of flight planes, set by the input of track points with known coordinates of ground-based landmarks with RTK kinematics rover GNSS implemented in previous phases (also useful in Processing phase for model scaling). The possibility of real-time control of the drone through a ground station has allowed detailed and accurate shooting of the works investigated, monitoring the position, the quota and the state of the device (Figure 7).

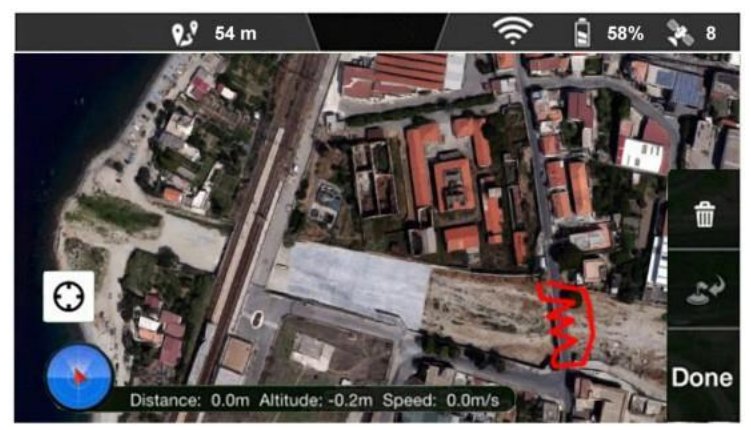

Figure 7. Ground station screen with flight plane

A number of shots were taken to fit the model, integrating, if necessary, shots by the drone with additional ground shots. The tables show the data for the various 3D models of the works surveyed (Tables 9, 11 and 13).

For reconstruction operations, Agisoft PhotoScan software, a low-cost commercial software produced by Agisoft LLC, has been used to create dense clouds, meshes and high quality textures. The workflow is fully automated both for image orientation and for generating and reconstructing the model. The generated model can be exported to be managed and eventually processed with external software dedicated to structural control (Figures 8, 10 and 12). All processes can be performed with various precision levels and different parameters can be set to improve the final result. For the work under review, we used a HP Z800 workstation with 2 x Xeon Hexa Core X5650 CPU, 64 GB RAM, 128GB SSD 2TB additional Hard Drive, equipped with two NVIDIA Quadro FX 4800 video cards 1.5 GB of RAM each and with 64-bit Windows 7 Professional operating system.

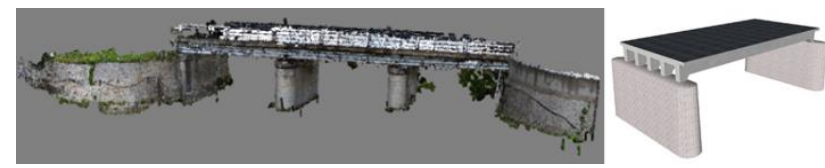

Figure 8. Point cloud and reconstructed mesh of San Gregorio's Bridge

\begin{tabular}{|c|c|c|c|c|c|c|}
\hline $\begin{array}{c}\text { No. } \\
\text { Photos }\end{array}$ & $\begin{array}{c}\text { No. } \\
\text { Sparse } \\
\text { Cloud } \\
\text { Points }\end{array}$ & $\begin{array}{c}\text { No. } \\
\text { Dense } \\
\text { Cloud } \\
\text { Points }\end{array}$ & $\begin{array}{c}\text { No. } \\
\text { Faces }\end{array}$ & $\begin{array}{c}\text { No. } \\
\text { Vertice } \\
\mathrm{s}\end{array}$ & $\begin{array}{c}\text { Survey } \\
\text { Time }\end{array}$ & $\begin{array}{c}\text { Processing } \\
\text { Time }\end{array}$ \\
\hline 252 & 1648473 & 117147723 & 1500000 & 834972 & $0.70 \mathrm{~h}$ & $14.39 \mathrm{~h}$ \\
\hline
\end{tabular}

Table 9. Summary Case Study San Gregorio Bridge 


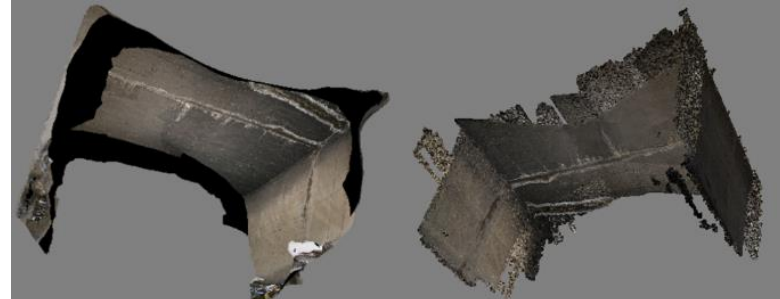

Figure 10. Texture of the San Gregorio tunnel with highlighted losers

\begin{tabular}{|r|c|c|c|c|c|c|}
\hline $\begin{array}{c}\text { No. } \\
\text { Photos }\end{array}$ & $\begin{array}{c}\text { No. } \\
\text { Sparse } \\
\text { Cloud } \\
\text { Points }\end{array}$ & $\begin{array}{c}\text { No. } \\
\text { Dense } \\
\text { Cloud } \\
\text { Points }\end{array}$ & $\begin{array}{c}\text { No. } \\
\text { Faces }\end{array}$ & $\begin{array}{c}\text { No. } \\
\text { Vertice } \\
\mathrm{s}\end{array}$ & $\begin{array}{c}\text { Survey } \\
\text { Time }\end{array}$ & $\begin{array}{c}\text { Processing } \\
\text { Time }\end{array}$ \\
\hline 44 & 201123 & 24814468 & 90000 & 45453 & $0.16 \mathrm{~h}$ & $2.87 \mathrm{~h}$ \\
\hline
\end{tabular}

Table 11. Summary Case Study San Gregorio Tunnel

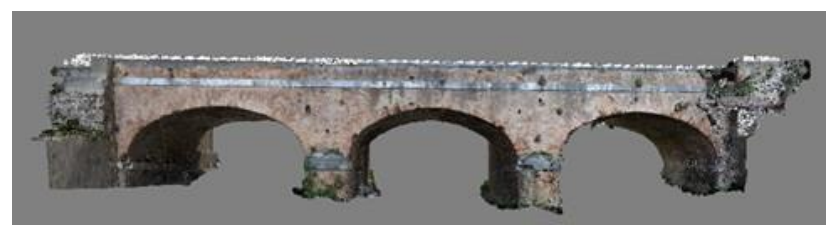

Figure 12. Texture of the Villa San Giovanni Bridge

\begin{tabular}{|c|c|c|c|c|c|c|}
\hline $\begin{array}{c}\text { No. } \\
\text { Photos }\end{array}$ & $\begin{array}{c}\text { No. } \\
\text { Sparse } \\
\text { Cloud } \\
\text { Points }\end{array}$ & $\begin{array}{c}\text { No. } \\
\text { Dense } \\
\text { Cloud } \\
\text { Points }\end{array}$ & $\begin{array}{c}\text { No. } \\
\text { Faces }\end{array}$ & $\begin{array}{c}\text { No. } \\
\text { Vertice } \\
\mathrm{s}\end{array}$ & $\begin{array}{c}\text { Survey } \\
\text { Time }\end{array}$ & $\begin{array}{c}\text { Processing } \\
\text { Time }\end{array}$ \\
\hline 322 & 2218887 & 100768566 & 22042863 & 11022176 & $1.00 \mathrm{~h}$ & $27.80 \mathrm{~h}$ \\
\hline
\end{tabular}

Table 13. Summary Case Study Villa San Giovanni Bridge

\section{COMPARISON WITH TLS}

To test what we get from the combination of APR and PhotoScan, the use of the Laser scanning technology has allowed to reconstruct a 3D model of the Villa San Giovanni bridge by point cloud, comparing in terms of precision, time and cost modeling between the two image based and range based methodologies (Dai et al., 2013). For the scanning of the work, we used a Riegl LMS-Z420i laser scanner. The survey is structured with the choice of instrument positions, its set-up, its calibration. Data acquisition and data processing are done with point cloud recording, filtering, data cleanup, modeling, and creating threedimensional mesh (Figure 14) (Barrile, Meduri, Bilotta, 2011).

The evaluation of the precisions was based on the 5 survey target placed on the deck facades and on the comparison of the results obtained with a traditional topographic survey with the Leica TCRA 1201 high precision automated station (Figure 15) (Barrile, Meduri, Bilotta, 2014a), (Barrile, Meduri, Bilotta, 2014b).

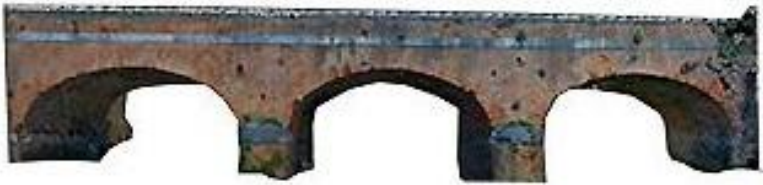

Figure 14. Texture of the Villa San Giovanni Bridge by Laser Scanner

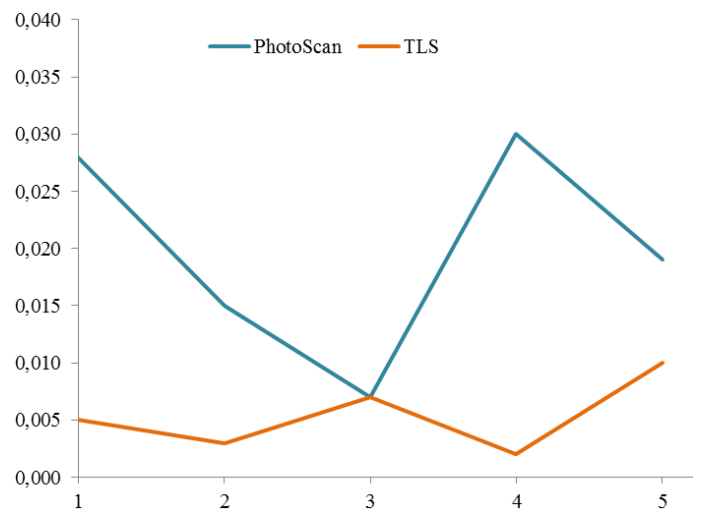

Figure 15. Error comparison $(\mathrm{cm})$ in the two systems

\section{CONCLUSIONS}

In this contribute, the survey with UAV and the SfM approach were used for the survey of three major artefacts in the province of Reggio Calabria. The SfM approach has its strengths in fast, low cost, and highly automated 3D production process. Processing times are greatly affected by the available computing power. With reference to the SfM approach, it should be pointed out, with appropriate step-by-step arrangements (camera type, number and position of shots, brightness and contrast), the point cloud and, consequently, the resulting pattern. They have a precision comparable to what we can get through the TLS survey by obtaining, in the cases in question, maximum errors in the order of $\pm 3 \mathrm{~cm}$ with respect to the real data (Dai, Feng, Hough, 2014). In generating point clouds, an overabundance of information, in some cases, has been translated into "noise" generation within the model generation. Furthermore, SfM technology can be used, besides modeling, for a first visual evaluation of structural degradation for works that are not directly and easily accessible using UAV.

\section{REFERENCES}

Bae, H., Golparvar-Fard, M., White, J., 2013. High-precision vision-based mobile augmented reality system for context-aware architectural, engineering, construction and facility management (AEC/FM) applications, Visual. Eng. 1(1), pp. 1-13.

Barrile, V., Meduri, G. M., Bilotta, G., 2009. Laser scanner surveying techniques aiming to the study and the spreading of recent architectural structures. In: Recent Advances in Computer Engineering, Proceedings of the 9th WSEAS International Conference on Signal, Speech and Image Processing, SSIP '09, Budapest. pp. 92-95.

Barrile, V., Meduri, G. M., Bilotta, G., 2011. Laser scanner technology for complex surveying structures. Wseas transactions on signal processing, Vol. 7, pp. 65-74. 
Barrile, V., Bilotta, G., 2014. Self-localization by Laser Scanner and GPS in automated surveys. Computational Problems in Engineering. Lecture Notes in Electrical Engineering, Springer, Vol. 307, pp. 293-313.

Barrile, V., Meduri, G. M., Bilotta, G., 2014a. Experimentations and Integrated Applications Laser Scanner/GPS for Automated Surveys. Wseas transactions on signal processing, Vol. 10, pp. 471-480.

Barrile, V., Meduri, G. M., Bilotta, G., 2014b. Comparison between Two Methods for Monitoring Deformation with Laser Scanner. Wseas transactions on signal processing, Vol. 10, pp. 497-503.

Barrile, V., Critelli, M., Lamari, D., Meduri, G..M., Pucinotti, R., Ricciardi, A., 2015. Applicazione di Sistemi di Scansione 3D e Fotogrammetrici al caso di un Ponte in C.A. In: Atti $16^{\circ}$ Convegno Aipnd Milano 21-23 Ottobre 2015.

Barrile, V., Lamari, D., Gelsomino, V., Sensini, P., 2016a. Modellazione 3D tramite Droni per Monitoraggi e Controlli. In: Atti $61^{\circ}$ Convegno Nazionale Sifet, 8-10 Giugno 2016, Lecce.

Barrile, V., Bilotta, G., D’Amore, E., Meduri, G.M., Trovato, S., 2016b. Structural Modeling of a Historic Castle Using Close Range Photogrammetry. International Journal of Mathematics and Computers in Simulation, Vol. 10, pp. 370-380.

Barrile, V., Bilotta, G., Meduri, G. M., 2016. Identifying damage on cars through the integrated use of TLS/SfM with thermographic images. International Journal of Circuits, Systems and Signal Processing, Vol. 10, pp. 433-439.

Barrile, V., Bilotta, G., Pozzoli, A., 2017. Comparison between innovative techniques of photogrammetry. In: The 2016 International Conference Applied Mathematics, Computational Science and Systems Engineering, Roma (Italia), 5-7 november 2016, ITM Web of Conferences, Vol. 9, pp. 1-7.

Bhatla, A., Choe, S., Fierro, O., Leite F., 2012. Evaluation of accuracy of as-built 3D modeling from photos taken by handheld digital cameras. Autom. Construct. Vol. 28, pp. 116127.

Dai, F., Lu, M., 2010. Assessing the accuracy of applying photogrammetry to take geometric measurements on building products. J. Construct. Eng. Manage. 136(2), pp. 242-250.

Dai, F., Dong, S., Kamat ,V., Lu, M., 2011. Photogrammetry assisted measurement of interstory drift for rapid post-disaster building damage reconnaissance. J. Nondestr. Eval. 30(3), pp. 201-212.

Dai, F., Rashidi, A., Brilakis, I., Vela, P., 2013. Comparison of image-based and time-of-flight-based technologies for three dimensional reconstruction of infrastructure. J. Construct. Eng. Manage. 139(1), pp. 69-79.

Dai, F., Feng, Y., Hough, R., 2014. Photogrammetric error sources and impacts on modeling and surveying in construction engineering applications. Visual. Eng. 2(1).

Golparvar-Fard, M., Bohn, J., Teizer, J., Savarese, S., PeñaMora, F., 2011. Evaluation of image-based modeling and laser scanning accuracy for emerging automated performance monitoring techniques. Autom. Construct. 20(8), pp. 1143-1155.
Klein, L., Li, N., Becerik-Gerber, B., 2012. Image-based verification of as-built documentation of operational buildings. Autom. Construct., Vol. 21, pp 161-171.

Koch, C., German Paal, S., Rashidi, A., Konig, M., Brilakis, I., 2014. Achievements and challenges in machine vision-based inspection of large concrete structures. Advan. Struct. Eng., 17(3), pp. 303-318.

Luhmann, T., Tecklenburg, W., 2001. Hybrid photogrammetric and geodetic surveillance of historical buildings for an urban tunnel construction. International Workshop on Recreating the Past Visualization and Animation of Cultural Heritage.

Malhotra, V.M., Carino, N.J., 1991. CRC Handbook on Nondestructive Testing of Concrete, CRC Press.

McCoy, A., Golparvar-Fard, M., Rigby, E., 2014. Reducing barriers to remote project planning: comparison of low-tech site capture approaches and image-based 3D reconstruction. $J$. Architect. Eng. 20(1).

Nahangi, M., Haas, C.T., 2014. Automated 3D compliance checking in pipe spool fabrication. Adv. Eng. Inform. 28(4), pp360-69.

Zhu, Z., Brilakis, I., 2009. Comparison of optical sensor-based spatial data collection techniques for civil infrastructure modelling. J. Comput. Civil Eng., 23(3), pp. 170-177. 